\section{Acesso a cuidados relativos à saúde sexual entre mulheres que fazem sexo com mulheres em São Paulo, Brasil}

\author{
Access to sexual health care for women who have \\ sex with women in São Paulo, Brazil
}

\begin{abstract}
This article focuses on the relationship between health care for women who have sex with women and representations of gender, sexuality, and the body. The study used ethnographic observation and in-depth interviews held from 2003 to 2006, with 30 women ranging from 18 to 45 years of age, belonging to different social segments, backgrounds, and sexual identities, living in Greater Metropolitan São Paulo. Analysis of the material pointed to greater difficulty in accessing gynecological care for lower-income women, those who had never had sex with men, or those with masculine body language. Not only the negative representations and experiences in relation to health services, but also identity constructions concerning gender and sexuality, are related to difficulties in accessing health care. Although a large share of the relevant international literature emphasizes the relationship between homophobia and decreased access to health services, the findings suggest that although situations involving discrimination are a reality, they were not considered impediments to the search for care, and were more associated with reporting of erotic practices and preferences at the services.
\end{abstract}

Health Services Accessibility; Female Homosexuality; Sexual Behavior
Regina Maria Barbosa 1,2

Regina Facchini ${ }^{3}$

\section{Introdução}

O enfrentamento das questões ligadas à homossexualidade feminina, e especificamente à sua relação com a saúde, enquanto campo de reivindicações de direitos, emerge no Brasil apenas recentemente, na virada do século XX para o XXI. Tal enfrentamento, que teve como início a noção de "direitos sexuais" como parte dos direitos humanos das mulheres, foi efetivado por meio de um processo político que conjugou expansão e maior visibilidade do movimento lésbico e sua articulação com o movimento feminista.

A partir de então, a pressão exercida por estes movimentos, no sentido da elaboração de políticas públicas de saúde que contemplem as necessidades desse grupo populacional, vem ganhando o apoio de gestores e técnicos de agências governamentais nas suas diferentes esferas, federal, estadual e municipal. Em junho de 2008, a I Conferência Nacional de Gays, Lésbicas, Bissexuais, Travestis e Transexuais (GLBT), ocorrida em Brasília, com o objetivo de elaborar propostas para o Plano Nacional de Promoção da Cidadania e Direitos Humanos de GLBT, aprovou documento que se constituiu instrumento de formalização das principais reivindicações dessa população.

A referência à homossexualidade feminina neste artigo não pretende remeter à idéia de uma população homogênea. Consideramos que a disjunção entre desejos, práticas e identidades, abundantemente registrada na literatura sobre 
sexualidade, e o entrecruzamento entre gênero, sexualidade e outros marcadores sociais de diferença (como raça, classe e geração) demandam atenção para a diversidade interna da população constituída por essa categoria.

Ao mesmo tempo, fica evidente o quadro de escasso conhecimento existente no Brasil relativo às necessidades de saúde dessa população. Tal realidade tem mobilizado um grupo, ainda pequeno, de pesquisadores brasileiros no sentido da produção de informação relevante que possa contribuir para a diminuição das lacunas existentes e o embasamento de tais políticas. O conhecimento sobre o acesso dessa população aos serviços de saúde, em especial aqueles voltados para saúde sexual e reprodutiva, é uma dimensão fundamental para a formulação de políticas de saúde adequadas.

Nesse sentido, a literatura internacional indica menor freqüência de realização de exames ginecológicos, de exames de Papanicolaou e de prevenção de câncer de mama entre as mulheres que fazem sexo com mulheres 1,2,3,4,5,6,7,8. Indica também que essas mulheres nem sempre procuram cuidados quando necessários ou só o fazem quando surgem sérios problemas e em períodos de maiores agravos à sua saúde; e que os profissionais de saúde solicitam menos a realização desses exames a essas mulheres 7,8,9,10.

A literatura aponta ainda que a menor procura pelos serviços de saúde está associada à existência de discriminação nos serviços de saúde, ao despreparo dos profissionais para lidar com as "especificidades" desse grupo populacional e às dificuldades das mulheres em revelar a homo ou a bissexualidade aos profissionais de saúde 11,12.

No Brasil, os dados existentes sobre acesso da população de mulheres que fazem sexo com mulheres a consultas ginecológicas e exames de prevenção coincidem com os achados internacionais. A proporção de mulheres que relatou nunca ter ido ao ginecologista variou nesses estudos de 3\% a 25\% 13,14,15,16,17,18. Em estudos conduzidos na cidade de São Paulo, observa-se que $18 \%$ a $35 \%$ de população de mulheres que fazem sexo com mulheres nunca haviam realizado o exame de Papanicolaou 16,17,18. Essas estimativas são maiores do que as encontradas para a população geral feminina residente na mesma cidade, $13,9 \% 19$

Tais dados sinalizam que um contingente significativo de mulheres que fazem sexo com mulheres encontra-se excluído dos serviços de atenção/cuidado à saúde. Realidade que tem sido analisada prioritariamente mediante hipóteses que enfatizam o contexto discriminatório dos serviços organizados em função de uma heterossexualidade presumida de suas usuárias, bem como a falta de qualificação e o preconceito dos profissionais.

Neste trabalho, assumimos o pressuposto de que tanto as representações e as experiências negativas em relação aos serviços de saúde, quanto as representações relativas a gênero, à sexualidade e ao próprio corpo mantêm relação com a dificuldade em acessar cuidados efetivos e integrais à saúde. Dessa forma, propõe-se analisar as representações e práticas relativas à saúde sexual de mulheres que fazem sexo com mulheres residentes na Grande São Paulo, tendo como ferramenta teórica estudos de gênero e sexualidade $20,21,22,23,24,25,26$. Assim, ao propor a discussão de aspectos que escapam à relação estabelecida entre homofobia e menor acesso a serviços ou assistência adequada à saúde sexual e reprodutiva, apontada por grande parte da literatura, pretende-se contribuir para o debate a respeito e fornecer subsídios para a formulação de políticas de saúde mais efetivas.

\section{Metodologia}

O projeto de pesquisa utilizou estratégias qualitativas (observação etnográfica e entrevistas em profundidade) para explorar a relação entre representações e práticas relativas aos cuidados de saúde, inclusive aquelas referentes aos profissionais e serviços de saúde, além das diferentes construções de gênero, identidade e estilos de vida encontradas na população em foco. O roteiro de entrevista incluiu questões sobre: perfil sóciodemográfico; história da vida sexual, reprodutiva e afetiva (explorando as construções de gênero e de identidade, as percepções a respeito do corpo e suas necessidades de saúde); estilo de vida (explorando o impacto da sexualidade sobre a construção de redes de sociabilidade e freqüência a ambientes específicos); história de saúde, percepção de riscos à saúde, adoção de estratégias de auto-cuidado, busca de serviços ou formas de atendimento às demandas de saúde e motivos e obstáculos a isso; e relação com profissionais e serviços de saúde.

Ao mesmo tempo, os estudos brasileiros apontam para o fato de que a construção de identidades e os modos de vivenciar questões relativas a gênero e sexualidade tendem a ocorrer de modo diverso em diferentes segmentos sócio-econômicos. Nesta perspectiva, a estratégia para compor a diversidade interna do grupo de entrevistadas partiu da inserção social em camadas médias e populares e do recrutamento das participantes em redes de sociabilidade claramente situadas nestes segmentos, buscando-se contemplar a diversidade em termos de raça/cor, 
idade e orientações/comportamentos sexuais. As redes sociais foram acessadas valendo-se de informantes-chave, localizadas em espaços de lazer e sociabilidade (bares, boates e restaurantes), de ativismo (feminista, lésbico e de luta contra a AIDS) e de serviços (públicos ou comunitários) de saúde.

No que diz respeito à definição conceitual da população, a escolha da categoria mulheres que fazem sexo com mulheres procurou evitar os problemas relativos à possibilidade de descompasso entre práticas/comportamentos e identidades sexuais, já descritos em pesquisas anteriores 27,28,29,30. Procurou-se evitar também que a busca pela convergência entre identidade e prática/comportamento dificultasse o acesso à diversidade de perfis e estilos de vida presentes na população, uma vez que estudos sobre homossexualidade realizados no contexto brasileiro têm associado uma maior possibilidade de convergência entre comportamento e identidade a determinados segmentos populacionais 27,28 .

Por conseguinte, a população do estudo foi composta por vinte mulheres de estratos populares e dez de estratos médios entre 18 e 45 anos, entrevistadas entre 2003 e 2006. Dessas mulheres, 16 se autoclassificaram como brancas, dez como pardas e quatro como pretas, diante das categorias do Instituto Brasileiro de Geografia e Estatística. Em relação à escolaridade, 18 tinham até Ensino Médio e o restante Ensino Superior completo. Com relação à situação conjugal, oito não tinham parceria fixa no momento da entrevista; 13 tinham parcerias sem coabitação; seis tinham parcerias com coabitação e três tinham parcerias heterossexuais sem coabitação. Das sete mulheres que tinham filhos, cinco os tiveram no âmbito de relacionamentos heterossexuais anteriores e duas, de relações homossexuais.

Do ponto de vista dos cuidados éticos, foi garantida às entrevistadas confidencialidade, sendo as mesmas identificadas apenas por um código sob o qual integraram o banco de dados. Cada entrevistada assinou um Termo de Consentimento Informado, conforme as indicações das Diretrizes e Normas Regulamentadoras de Pesquisas Envolvendo Seres Humanos (Resolução $n^{\circ}$. 196/96). O projeto foi submetido e aprovado pelo Comitê de Ética em Pesquisa do Centro de Referência e Treinamento DST/AIDS em São Paulo.

\section{Resultados}

\section{Acesso a cuidados ginecológicos}

A primeira distinção digna de nota no conjunto das entrevistadas diz respeito ao acesso a cuida- dos ginecológicos, mais especificamente à consulta ginecológica e ao exame de Papanicolaou, escolhidos como foco privilegiado de análise por constituírem condutas universalmente recomendadas às mulheres: metade das entrevistadas relatou acesso à consulta ginecológica com regularidade anual. Para o restante das entrevistadas, 0 acesso aconteceu apenas esporadicamente, motivadas por demandas pontuais, ou nunca procuraram ginecologista. Quanto à realização do exame de Papanicolaou, a situação se mostrou similar: do total de mulheres, sete nunca haviam realizado exame; cinco, apenas uma vez - destas, três o fizeram como parte de um protocolo de pesquisa.

Embora um fator comumente associado, e enfatizado na literatura científica, ao menor acesso a cuidados ginecológicos seja pertencer a segmentos populares 31,32 , neste estudo tal associação se verificou apenas em mulheres que conjugavam tal pertencimento de classe a trajetórias afetivo-sexuais marcadas por pouco ou nenhum contato sexual com homens. O conjunto de entrevistadas com vivência marcadamente heterossexual no passado (tal denominação busca somente introduzir uma distinção com relação às mulheres para quem a experiência com parceiros masculinos teve caráter pontual ou de experimentação), ou com prática bissexual atual, referiu visita ao ginecologista uma ou mais vezes ao ano, independentemente da inserção de classe.

Ainda que, entre as usuárias de serviço público, tenham sido muito comuns queixas sobre a qualidade do atendimento médico, não apenas do ginecologista, especialmente no tocante ao tempo da consulta e à relação profissionalpaciente, tais queixas não foram articuladas no discurso das mulheres como justificativa para deixar de procurar atendimento ginecológico.

Os relatos sobre a primeira visita ao ginecologista reforçam a importância de fatores associados a convenções sociais de gênero ao apontarem, como as principais vias de acesso, o início da vida (heteros) sexual e a maternidade. Os motivos de busca mais comuns remetem a problemas/ incômodos ou a momentos socialmente valorizados no reconhecimento do sujeito como mulher: a primeira menstruação, a primeira relação (heteros)sexual ou a possibilidade de gravidez. Na mesma direção apontam as pesquisas realizadas com a população feminina em geral 31 .

De outro lado, a análise do material sugere presença de uma relação entre atributos e posturas corporais auto-referidos com base em categorias como "masculina" ou "mais masculinizada" e menor freqüência a serviços de saúde ginecológica. Todas as mulheres, independente de sua in- 
serção sócio-econômica, que usaram expressões como "masculinizada" ou "mais masculina" para referir-se a si mesmas estão entre aquelas que tiveram freqüência baixa e irregular de realização de exames ginecológicos e de Papanicolaou, ou nunca os realizaram.

Tais dados coincidem com o que já foi apon tado por outras pesquisas brasileiras. A associação entre busca por cuidados ginecológicos e ter sexo com homens também está presente nos dados de Meinerz 33. A relação entre "masculinização" e menor freqüência a ginecologistas também foi identificada em uma pesquisa em bairros de periferia na Grande São Paulo 16.

Para além das questões até aqui assinaladas, representações acerca de riscos e necessidades de saúde, do próprio corpo e da consulta ginecológica se mostraram relacionados à freqüência ao ginecologista e à realização do Papanicolaou.

\section{Percepção de riscos e de necessidades de cuidado}

Entre aquelas que tiveram nenhuma ou poucas consultas sem regularidade foi muito comum a referência à ausência de "necessidade". Essa argumentação incluiu a "falta de necessidade" por "não ter corrido riscos" e por "ausência de sintomas". "A outra vez que eu fui [segunda e última vez], as meninas [colegas de trabalho] marcaram pra mim para o dia seguinte; foi mais um lance de comodidade, porque na época eu estava com cólicas terríveis. E aí eu fui, passei, ele só conversou comigo e pediu um ultra-som, acabei que nem levei o tratamento adiante, nem fui fazer o ultrasom. Até fui marcar, esqueci do dia e não fui. Mas, assim, eu nunca tive problemas, nem nunca tive problema de corrimento, esses negócios. Eu nunca tive nada que me levou ao ginecologista, entendeu? Seria assim, sabe, só exames de rotina; nada que tenha me levado. Nunca precisei ir tomar anticoncepcional, então..." (23 anos, auxiliar de enfermagem em maternidade de referência para HIV, poucas relações com homens no início da vida sexual).

"De saúde, eu sou meio relaxada... a gente se acomoda muito, a gente acha que não sai com homens, essas coisas. Eu sei que tem que fazer exame, mas eu sou meio preguiçosa mesmo... Eu não me preocupo muito; como eu não sinto nada, a pessoa se acomoda... Não senti necessidade. Eu sempre confiei nas pessoas que eu andei" (39 anos, copeira desempregada, nunca fez sexo com homens).

O conjunto das entrevistadas que não mantiveram freqüência anual ao ginecologista fez referência, em diferentes momentos da entrevista, à existência de uma suposta diferença entre as necessidades de saúde das mulheres que fazem sexo com homens e das que fazem sexo com mulheres. Entre essas, foram recorrentes representações que associam DST a homens - "é mais fácil pegar uma DST de um homem”, DST são "doenças de homens" ou "provenientes do homem" -, revelando uma valoração do "homem" como "promíscuo" e "sujo".

"Eu não critico bissexual, desde o momento em que ele não esteja comigo! Desde que eu não tenha uma parceira que transa com os caras. Porque eu acho super perigoso! Eu acho um lance muito perigoso. Eu procuro assim uma pessoa na mesma idade, ou mais velha que eu e pelo menos não tenha tanto atrativo com os meninos. Por causa dessa coisa da sexualidade e da DST também. É mais fácil. É mais fácil você se contaminar com os caras do que com as mulheres, eu acho, porque eles são mais promíscuos" (36 anos, auxiliar de enfermagem, nunca fez sexo com homens).

Assim, a mulher que mantém relações sexuais com homens - como se contaminada pela desqualificação moral que a eles se aplica - é apontada como fonte de riscos à saúde (ver Douglas 34 sobre a relação entre os sistemas classificatórios e as concepções de puro e impuro, e de poluição). Essa idéia de "contaminação" ou "poluição" presente no contato sexual com homens parece ter como contrapartida a atribuição de um caráter protetor ou de ausência de risco no contato entre mulheres, noção que ancora a menor busca por cuidados preventivos. Dados semelhantes estão presentes em Meinerz ${ }^{33}$. Apenas uma mulher com freqüência regular ao ginecologista expressou tal concepção que, por outro, lado esteve muito presente entre aquelas que tiveram menos contatos sexuais com homens ao longo da vida e entre as com mais de 35 anos. Coincidentemente, as representações acerca do ginecologista, por parte destas mulheres, têm por referência um profissional que trata de DST enquanto doença proveniente do sexo com homens, do qual, portanto, prescindem.

Com relação à percepção de riscos e de necessidades de cuidado associados às DST/AIDS, observa-se uma situação semelhante. A noção de que a "AIDS não passa na relação entre mulheres" ou que é "algo com que não precisa se preocupar" foi recorrente na fala das mulheres com mais de 35 anos e, somam-se aqui, as mulheres mais jovens com parcerias fixas. As mulheres mais jovens, especialmente as que não tinham parceria fixa no momento da entrevista e as que tinham comportamento bissexual, nesse caso mesmo as mais velhas, são as que mais referiram essa preocupação. Do ponto de vista de acesso a tecnologias de prevenção, a noção de ausência de risco de infecção pelo HIV desdobra-se no relato pouco expressivo de realização de teste sorológico: a 
maior parte das entrevistadas nunca fez teste de HIV ou o fez ao doar sangue.

De modo geral, a preocupação com AIDS foi menos recorrente do que com outras DST. A busca de serviços de saúde voltados especificamente para DST foi menos referida do que a procura por ginecologistas: como relatado em outros trabalhos brasileiros 1,35. A noção de DST encontrase associada à idéia de promiscuidade e traição e, principalmente, com o fato de ter sexo com homens.

As entrevistas revelam falta de informações adequadas sobre DST, mesmo entre as que já tiveram diagnóstico e trataram alguma DST. Poucas entrevistadas relataram acesso a informações específicas sobre prevenção às DST/AIDS entre mulheres, e algumas - sobretudo as mais velhas e que mantêm relações sexuais exclusivamente com mulheres - também não manifestaram qualquer demanda de informação nesse sentido. A demanda por orientações específicas é restrita às mulheres mais jovens, mais escolarizadas e particularmente entre as que mantêm relações sexuais com mulheres há menos tempo.

A solução mais comum para essa demanda consiste na busca de informações em livros, páginas da Internet ou em organizações da sociedade civil que trabalham com prevenção à DST/ AIDS. Entre as mulheres mais velhas, a fonte de informação são outras mulheres que fazem sexo com mulheres, especialmente a própria parceira, fazendo com que prevenção à DST seja encarada como um "assunto do casal" e não algo que passe pela orientação de um profissional de saúde.

Entre as poucas que tiveram acesso a informações e citaram insumos como barreiras ou luvas, nenhuma considerou viável sua utilização cotidiana. Nesse contexto, marcado por falta de informação e/ou por informações cuja aplicabilidade cotidiana não é tida como viável, é recorrente o relato de práticas que remetem à noção de higiene, tais como a verificação do asseio e cuidados com a aparência, o ato de cheirar e/ou observar os genitais da parceira, como forma de prevenção. Outras práticas referidas incluem a recusa de parceiras que relatem, nos primeiros contatos, histórico de uso de drogas ou se identifiquem como bissexuais, num recurso que remete à noção de "grupos de risco".

A hierarquização de práticas associadas a "maior ou menor risco" não é comum a todas as entrevistadas, concentrando-se entre as que possuem mais informações e maior preocupação com a questão da AIDS. Essa hierarquização, quando existente, está focada especialmente em práticas em que há troca direta de fluidos genitais (contato entre genitais) ou contato entre boca e região genital, consideradas como de "maior risco", e usa por referência as informações sobre prevenção ao HIV disseminadas nos meios de comunicação e cartilhas de prevenção. Assim como ocorre em outras populações, a restrição de práticas consideradas "de maior risco" deixa de ser adotada na medida em que sentimentos de confiança e intimidade entram em cena no relacionamento. As expectativas de fidelidade $\mathrm{e}$ a sua articulação com saúde sexual coincidem com o apontado por outros trabalhos 1,35. De outro lado, outras práticas que podem igualmente estar associadas à transmissão sexual de DST/ HIV, como abuso de substâncias - inclusive uso de drogas injetáveis, sexo sem preservativo com homens gays e heterossexuais, múltipla parceria, sexo com parceira soropositiva e troca de sexo por drogas ou dinheiro - foram registradas em algumas entrevistas.

\section{Representações sobre o corpo e o exame ginecológico}

A consulta ginecológica aparece como um momento extremamente delicado tanto para o profissional de saúde quanto para a mulher. Envolve uma série de mediações - que passam por representações sobre o corpo, sobre o próprio exame físico e experiências anteriores com os profissionais de saúde - que serão a seguir explicitadas.

Para a maior parte das entrevistadas, a consulta é vista como lócus de exposição da intimidade corporal. Intimidade que compreende não só a exposição do corpo em si como de comportamentos reconhecidos como socialmente desvalorizados, que não necessariamente seriam "aceitos" pelo ginecologista. Apesar disso, o receio de tratamento inadequado resultante da exposição das preferências ou práticas eróticas foi pouco mencionado como algo que chegasse a impedir a ida ao ginecologista. Diferentemente, a decisão de relatar ou não ao ginecologista as preferências ou práticas eróticas foi bastante problematizada pelas entrevistadas. A tomada de decisão a esse respeito implica sempre uma reflexão anterior e uma avaliação do risco de passar por discriminação.

As dificuldades mais recorrentes com relação ao exame ginecológico referem-se à vergonha da exposição do corpo nu para um estranho, a incômodos com relação à posição para o exame, descrita como "muito constrangedora", e ao toque vaginal durante o exame (o desconforto não constitui referência específica desse grupo de mulheres, sendo recorrente também entre mulheres com experiência exclusivamente heterossexual 32). Embora presente no conjunto de mulheres, este desconforto assume relevância apenas na fala daquelas que vão com menor 
freqüência ao ginecologista (que, é importante lembrar, são as mesmas mulheres que utilizaram termos como "masculina" em referência a si mesmas). Mais da metade dessas mulheres fez alusão ainda à noção de que o exame ginecológico pode "machucar" ou "doer mais" quando não se tem sexo com homens ou práticas sexuais que envolvam a penetração.

Não só a presença de atributos externos ou de posturas corporais, auto-referidas como "masculinizadas", como também atributos corporais expostos pelo exame ginecológico, são percebidos como sinais capazes de denunciar uma sexualidade "desviante". Não seria necessário, portanto, o relato verbal para que o profissional conheça a orientação sexual da mulher ou saiba que há algo "diferente" com sua sexualidade. Se para um grupo de mulheres tais aspectos adquirem relevância a ponto de impedir a procura e a realização de exames e procedimentos que envolvam a exposição do corpo, para outras entrevistadas tais aspectos constituem os motivos que levam ao relato de sua orientação sexual ao profissional de saúde.

"P: E quando você contou para o médico que você era entendida, você contou para ele pensando em quê?". "R: De ele poder fazer um exame, alguma coisa e dizer, 'engraçado, que estranho...' Eu acho que uma mulher tendo relação com homem é totalmente diferente, entendeu? Até o toque que a mulher faz na gente é diferente da relação como homem. Então, ele podia até notar alguma coisa. Então, eu já falo: 'antes de você fazer alguma coisa, fazer algum exame, eu sou entendida e moro com mulher"' (39 anos, copeira desempregada, nunca fez sexo com homens).

Entre as entrevistadas que já foram ao ginecologista, a maioria relatou a orientação sexual ao profissional, o que não necessariamente se desdobrou no recebimento de uma conduta adequada, ao contrário do que a suposição de "sair do armário" como uma solução unilateral para a melhora dos cuidados à saúde de mulheres que fazem sexo com mulheres possa fazer crer.

O relato sobre a orientação sexual aconteceu geralmente durante a coleta da história clínica particularmente depois de perguntas que pressupõem a heterossexualidade - ou após indicação de tratamento do parceiro sexual. A maior parte das mulheres que relatou a orientação sexual ao ginecologista disse fazê-lo para procurar "direcionar a consulta” à sua experiência, evitando assim perguntas que consideram inadequadas à sua realidade ou evitar usar o tempo escasso da consulta com questões que não lhe dizem respeito. Os resultados a respeito da motivação para relatar a orientação ou práticas sexuais ao profissional coincidem com os encontrados por Meinerz 33.
Nesse sentido, vale a pena mencionar que metade das entrevistadas referiu falta de conhecimento acerca das práticas sexuais entre mulheres e de informações sobre prevenção por parte dos profissionais de saúde. Entre as mulheres que relatam ao ginecologista sua orientação sexual esperando em contrapartida alguma orientação específica, foi comum o desapontamento pelo fato de o profissional não estar preparado para atendê-las com a mesma desenvoltura e habilidade, acessando muitas vezes uma série de conhecimentos estereotipados como guia para sua conduta durante a consulta.

“Não, não diria que tenho uma relação boa. Não em relação a mim, mas eu acho que os profissionais de ginecologia, eles fazem diferenciação, sabe. Eles não te abordam assim 'qual sua opção sexual?' Eles te abordam assim: 'Qual o método anticonceptivo que você usa?' Ou: 'você usa camisinha?' 'Não'. 'Você usa anticoncepcional?' 'Não'. 'Então o quê você usa?' Eles já partem do pressuposto que você é hetero. Ai você fala 'não, não uso porque eu sou homossexual'. E aí a fisionomia muda. Dizem 'ah tá!' e aí abaixa a cabeça. Não deveria ser um 'ah tá!', né? E aí, as perguntas não passam a ser voltadas pelo fato de você ser homossexual. Não, não tem essa! Aí, pulam essa parte todinha, sabe? Vamos partir para o exame! Eu não sei, eu acho que eles não imaginam como seja a relação sexual de homossexuais femininos. Porque eles não perguntam se tem penetração anal, não perguntam nada! Eu acho que isso é falta de informação do profissional. E eles se sentem constrangidos. Impressionante. ...Eu acho que pode ser até um lance de segurança, que pelo fato deles terem um homossexual na frente, eles não se sentem seguros. Sabe, eles não dão vazão a você questionar. Meu, aquele lance: 'Ai não vamos falar muito, vamos ser diretos, vamos ser objetivos. Se fizer alguma pergunta, eu não vou saber responder"' (25 anos, estudante de curso técnico em enfermagem, teve sexo com homens no início da vida sexual).

Vários episódios de tratamento inadequado relacionados ao relato da orientação sexual foram descritos por entrevistadas. Os episódios envolviam mudança de atitude por parte do profissional, comentários preconceituosos, ausência de oferta de exames clínicos, de mamas ou Papanicolaou. A queixa mais comum refere-se ao fato de o profissional, após o relato, agir como se não tivesse recebido a informação ou como se não tivesse nada a comentar ou orientar a respeito.

"O tratamento é completamente diferente. Quando eu me relacionava com homens eles orientavam. A primeira coisa que eles diziam: 'olha, tem que usar o anticoncepcional, olha a camisinha!'; 'olha, se contamina assim!' Tinha toda 
uma diferença. Acho que pelo fato de a gente ser homossexual e não ter a eventual possibilidade de uma gravidez, eles não se preocupam com a prevenção. Mas deveriam, porque a incidência de contaminação com DST pode ser tão grande quanto a de um hetero" (25 anos, estudante de curso técnico em enfermagem, teve sexo com homens no início da vida sexual).

“A minha ginecologista é minha ginecologista e é ginecologista da minha mãe, ela me pegou de menina, me atendeu quando eu casei, ela conhecia todas as histórias de violência com meu exmarido e tal. Aí eu contei a ela que estava namorando uma mulher e consegui o meu objetivo [que a médica solicitasse exames de DST e AIDS], porém fiquei muito constrangida. ...Uma coisa que ela [a ginecologista] não fez, que ela sempre fazia, era examinar meu seio. Eu achei muito estranho. Saí de lá pensando: 'pô, ela sabe que eu tenho... tenho um histórico de quem pode ter e ela não me examinou'. Eu não sei se ela esqueceu, mas eu também não falei, entendeu? Eu já sabia, dentro do consultório, que ela não tinha me examinado, mas eu saí de lá e não falei: 'olha, a senhora não examinou meus seios' e tal' (25 anos, gerente administrativa, foi casada com um homem entre os 14 e os 25 anos e há 5 meses se relacionava com uma mulher).

As entrevistas indicaram, ainda, a necessidade de que profissionais de saúde tenham cuidado ao lidar com categorias de classificação presentes na população, já que o significado de palavras como "lésbica" ou "bissexual" pode não ser o mesmo para o profissional e para sua interlocutora, como referido também nos estudos de Meinerz ${ }^{33}$, Facchini ${ }^{1}$ e Almeida 36 : "P: O que éque você chama de mulher bissexual?". "R: A biéaquela que quer os dois relacionamentos ao mesmo tempo. Quer estar comigo e manter uma relação com um homem". "P: Se ela teve um relacionamento com homem até três meses atrás, isso..." "R: Se ela foi casada, separou, não quer mais se relacionar com homem, nem com aquele homem, nem com nenhum outro, quer se relacionar com mulher, ela é entendida" (44 anos, auxiliar de enfermagem, teve sexo com homens até os vinte e poucos anos).

Além da variação do significado associado a categorias de classificação, é importante lembrar que, embora expressem a identidade sexual da mulher no momento da consulta, tais termos não necessariamente refletem as práticas sexuais mantidas ou a trajetória sexual e reprodutiva. Fato que reforça a necessidade, também expressa em Pinto ${ }^{37}$, de que a coleta de informações em consultas ginecológicas não pressuponha heterossexualidade e de que o profissional investigue as trajetórias sexuais e reprodutivas, evitando pressuposições ligadas a estereótipos. No aconselhamento quanto à prevenção de DST/AIDS, é importante investigar as práticas sexuais efetivamente mantidas, uma vez que podem variar consideravelmente e não mantêm relação com os termos usados pelas mulheres para a autoclassificação.

\section{Comentários finais}

Embora boa parte da bibliografia internacional sobre acesso a cuidados ginecológicos entre mulheres que fazem sexo com mulheres faça referência à relação entre homofobia e menor acesso a serviços, os dados desta pesquisa sugerem que, apesar de as situações envolvendo discriminação e preconceito por parte do profissional constituírem uma realidade, elas não foram consideradas como impedimentos para a ida ao ginecologista. $\mathrm{O}$ receio e a idéia de preconceito estiveram muito mais associados à decisão de relatar ou não ao profissional as práticas e preferências eróticas.

No entanto, entre mulheres que possuem atributos e posturas corporais "masculinizados", a consulta ginecológica adquire um significado de explicitar e "denunciar a sexualidade", que somado às representações referentes aos riscos e às necessidades de mulheres que fazem ou não sexo com homens, tornam a relação com a busca por cuidados ginecológicos especialmente complexa e difícil.

Os resultados deste estudo apontam para a necessidade de refinar a abordagem da questão do acesso a cuidados ginecológicos entre mulheres que fazem sexo com mulheres, levando em conta a diversidade dessas mulheres, de suas experiências e as diferentes representações que têm sobre o próprio corpo, o risco de adoecimento e o papel da busca por cuidados ginecológicos, de modo a produzir ações mais efetivas no sentido de reduzir as dificuldades ao acesso. Partir da idéia genérica de "homofobia" por parte dos serviços talvez não seja o suficiente para ajudar a identificar áreas de vulnerabilidade situadas nos entrecruzamentos de sexualidade, gênero, classe e geração que dificultam o acesso aos serviços ou o relato da orientação sexual 34 .

Como último comentário, gostaríamos de chamar a atenção para a necessidade de ampliação do debate político e do conhecimento relativos aos problemas que essa população tem para acessar cuidados adequados às suas necessidades de saúde. Sem dúvida, parte das dificuldades de acesso deve ser discutida no âmbito das fragilidades das políticas públicas de saúde no Brasil e, no caso das mulheres, de uma atenção à saú- 
de restrita às suas dimensões reprodutivas apesar das duas décadas passadas desde a criação do Programa de Assistência Integral à Saúde da Mulher (PAISM) ${ }^{38}$. Por outro lado, é igualmente verdade que um olhar específico para as necessidades de saúde desse grupo populacional só foi incorporado muito recentemente no âmbito das políticas de saúde de enfrentamento da epidemia do HIV/AIDS.

Portanto, a escassa produção científica abordando a temática saúde e homossexualidade feminina no Brasil, a inexistência de políticas de

\section{Resumo}

O objetivo deste trabalho é investigar a relação entre adoção de cuidados à saúde entre mulheres que fazem sexo com mulheres e as representações relativas a gênero, sexualidade e ao corpo. O estudo utilizou observação etnográfica e entrevistas em profundidade, realizadas entre 2003 e 2006, com trinta mulheres entre 18 e 45 anos, de diferentes segmentos sociais, trajetórias e identidades sexuais, residentes na grande São Paulo, Brasil. A análise do material aponta maior dificuldade em acessar cuidados ginecológicos entre mulheres das camadas populares; que nunca tiveram sexo com homens ou que possuem uma gramática corporal masculinizada. Não só as representações e as experiências negativas em relação aos serviços de saúde, mas também as construções identitárias relativas a gênero e sexualidade estão relacionadas às dificuldades em acessar cuidados à saúde. Embora boa parte da bibliografia internacional a respeito enfatize a relação entre homofobia e menor acesso a serviços, os resultados sugerem que apesar de as situações envolvendo discriminação constituírem realidade, elas não foram consideradas impedimentos para a busca de cuidado, estando muito mais associadas ao relato das práticas e preferências eróticas nos serviços.

Acesso a Serviços de Saúde; Homossexualidade Feminina; Comportamento Sexual saúde consistentes para o enfrentamento das dificuldades e necessidades desta população, o parco conhecimento sobre suas demandas e a ausência de tecnologias de cuidado à saúde adequadas - aliados à persistência de pré-noções e preconceitos - convertem-se, no âmbito da saúde pública, em desperdício de recursos, em constrangimento durante o atendimento, em assistência inadequada e, muito provavelmente, em um grande contingente de mulheres com problemas de saúde não diagnosticados e não tratados.

\section{Colaboradores}

R. M. Barbosa e R. Facchini participaram igualmente da elaboração do artigo, análise e discussão dos resultados.

\section{Agradecimentos}

O projeto de pesquisa foi apoiado pelo Conselho Nacional de Desenvolvimento Científico e Tecnológico (CNPq) e pelo IX Programa Interinstitucional de Metodologia de Pesquisa em Gênero, Sexualidade e Saúde Reprodutiva, coordenado pelo Núcleo de Estudos de População, Universidade Estadual de Campinas (NEPO/UNICAMP), em parceria com o Instituto de Medicina Social, Universidade do Estado do Rio de Janeiro (IMS/UERJ), MUSA - Programa Integrado de Pesquisa e Cooperação Técnica em Gênero e Saúde, Instituto de Saúde Coletiva, Universidade Federal da Bahia (ISC/ UFBA) e Fundação Ford. 


\section{Referências}

1. Facchini R. Entre umas e outras: mulheres, (homo)sexualidades e diferenças na cidade de São Paulo [Tese de Doutorado]. Campinas: Instituto de Filosofia e Ciências Humanas, Universidade Estadual de Campinas; 2008.

2. Aaron DJ, Markovic N, Danielson ME, Honnold JA, Janosky JE, Schmidt NJ. Behavioral risk factors for disease and preventive health practices among lesbians. Am J Public Health 2001; 91:972-5.

3. Diamant AL, Wold C, Spritzer K, Gelberg L. Health behaviors, health status, and access to and use of health care: a population-based study of lesbian, bisexual, and heterosexual women. Arch Fam Med 2000; 9:1043-51.

4. Denenberg R. Report on lesbian health. Womens Health Issues 1995; 5:81-91.

5. Diamant AL, Schuster MA, Lever J. Receipt of preventive health care services by lesbians. Am J Prev Med 2000; 19:141-8.

6. Fethers K, Marks C, Mindel A, Estcourt CS. Sexually transmitted infections and risk behaviours in women who have sex with women. Sex Transm Infect 2000; 76:345-9.

7. Marrazzo JM, Stine K, Koutsky LA. Genital human papillomavirus infection in women who have sex with women: a review. Am J Obstet Gynecol 2000; 183:770-4

8. Rankow EJ. Lesbian health issues for the primary care provider. J Fam Pract 1995; 40:486-96.

9. Rankow EJ, Tessaro I. Cervical cancer risk and Papanicolaou screening in a sample of lesbian and bisexual women. J Fam Pract 1998; 47:139-43.

10. Roberts SJ, Sorensen L. Lesbian health care: a review and recommendations for health promotion in primary care settings. Nurse Pract 1995; 20: 42-7.

11. Bernhard LA. Lesbian health and health care. Annu Rev Nurs Res 2001; 19:145-77.

12 Bergeron S, Senn CY. Health care utilization in a sample of Canadian lesbian women: predictors of risk and resilience. Women Health 2003; 37:19-35.

13. Boehmer U, Case P. Physicians don't ask, sometimes patients tell: disclosure of sexual orientation among women with breast carcinoma. Cancer 2004; 101:1882-9.

14. Andersson D, Westerstahl A. Gynecologists about lesbian women: an interview study. There is a risk that lesbian women receive worse treatment. Lakartidningen 2000; 97:5796-800.

15. Coordenação Nacional de DST e AIDS. Pesquisa de opinião pública - mulheres que fazem sexo com mulheres. http://www.aids.gov.br/final/novi dades/Mulheres.ppt (accessed on 20/Jan/2003).

16. Granado L. Mitos sobre a relação entre mulheres e a transmissão de DST/HIV. Boletim Ousar Viver 1998; 4:4-6.

17. Carrara S, Ramos S, Simões JA, Facchini R. Política, direito, violência e homossexualidade. Pesquisa 10a Parada do Orgulho GLBT-Rio 2005. Rio de Janeiro: Centro de Estudos e Pesquisa em Saúde Coletiva, Instituto de Medicina Social, Universidade do Estado do Rio de Janeiro; 2006.
18. Minas de Cor-Espaço de Cidadania e Cultura. Novos contornos: lésbicas da periferia. São Paulo: Minas de Cor-Espaço de Cidadania e Cultura; 2005.

19. Coelho LM. A representação social da homossexualidade feminina nos ginecologistas do ponto de vista das mulheres lésbicas e bissexuais. Revista Tesseract 2001; 4. http://tesseract.sites.uol. com.br/textoleilacoelho.htm (acessado em 03/ Jan/2006).

20. Pinto VM, Tancredi MV, Tancredi NA, Buchalla CM. Sexually transmitted disease/HIV risk behaviour among women who have sex with women. AIDS 2005; 19 Suppl 4:S64-9.

21. Pinho AA. Fatores associados à realização do teste de Papanicolaou entre mulheres em idade reprodutiva no município de São Paulo [Dissertação de Mestrado]. São Paulo: Faculdade de Saúde Pública, Universidade de São Paulo; 2002.

22. Brah A. Diferença, diversidade, diferenciação. Cadernos Pagu 2006; (26):329-76.

23. Foucault M. História da sexualidade. I: a vontade de saber. Rio de Janeiro: Edições Graal; 1980.

24. Rubin G. The traffic in women. Notes on the "political economy” of sex. New York: Monthly Review Press; 1975.

25. Rubin G. Thinking sex: notes for a radical theory of the politics of sexuality. In: Vance C, editor. Pleasure and danger. exploring female sexuality. Boston: Routledge and Kegan Paul; 1984. p. 267-319.

26. Scott JW. Gender and the politics of history. New York: Columbia University Press; 1988.

27. Vance C. Antropology rediscovers sexuality: a theoretical comment. Soc Sci Med 1991; 33:875-84.

28. Weeks J. Sexuality. New York: Routledge; 1986.

29. Fry P. Da hierarquia à igualdade: a construção histórica da homossexualidade no Brasil. In: Fry P, organizador. Para inglês ver: identidade e política na cultura brasileira. Rio de Janeiro: Jorge Zahar Editor; 1982. p. 87-115.

30. Heilborn ML. Ser ou estar homossexual: dilemas de construção de identidade social. In: Parker RG, Barbosa RM, organizadores. Sexualidades Brasileiras. Rio de Janeiro: Relume Dumará/Associação Brasileira Interdisciplinar de AIDS/Instituto de Medicina Social, Universidade do Estado do Rio de Janeiro; 1996. p. 136-45

31 Martins LFL Thuler LCS, Valente JG. Cobertura do exame de Papanicolaou no Brasil e seus fatores determinantes: uma revisão sistemática da literatura. Rev Bras Ginecol Obstet 2005; 27:485-92.

32 Torres MEA, Miranda-Ribeiro P, Machado CJ. "Vai lá, tira a roupa... e... pronto...”: o acesso a consultas ginecológicas em Belo Horizonte, MG. Rev Bras Estud Popul 2008; 25:49-69.

33. Meinerz NE. Método cien por ciento garantizado. Prácticas de sexo seguro en las relaciones homoeróticas entre mujeres de segmentos medios en Porto Alegre. Boletín Eletrónico del Proyecto Sexualidades, Salud y Derechos Humanos en América Latina 2005; 2(16). http://www.ciudadania sexual.org/boletin/b16/articulos.htm\#2 (acessado em 21/Dez/2005). 
34. Douglas M. Pureza e perigo: uma análise dos conceitos de poluição e tabu. São Paulo: Editora Perspectiva; 1976.

35. Meinerz NE. Entre mulheres - estudo etnográfico sobre a constituição da parceria homoerótica feminina entre mulheres de camadas médias na cidade de Porto Alegre [Dissertação de Mestrado]. Porto Alegre: Universidade Federal do Rio Grande do Sul; 2005.

36 Almeida GES. Da invisibilidade à vulnerabilidade: percursos do 'corpo lésbico' na cena pública face à possibilidade de infecção por DST e AIDS [Tese de Doutorado]. Rio de Janeiro: Instituto de Medicina Social, Universidade do Estado do Rio de Janeiro; 2005
37 Pinto VM. Aspectos epidemiológicos das doenças sexualmente transmissíveis em mulheres que fazem sexo com mulheres [Dissertação de Mestrado]. São Paulo: Faculdade de Saúde Pública, Universidade de São Paulo; 2004.

38. Giffin K. Pobreza, desigualdade e eqüidade em saúde: considerações a partir de uma perspectiva de gênero transversal. Cad Saúde Pública 2002; 18 Suppl:103-12.

Recebido em 11/Jul/2008

Versão final reapresentada em 24/Out/2008

Aprovado em 18/Nov/2008 